\title{
Revista
}

\section{Elección de gobernadores regionales y descentralización territorial en Chile*}

\author{
Eduardo Guillermo Castillo Vigouroux ${ }^{* *}$
}

Fecha de recepción: 12 de diciembre de 2017

Fecha de evaluación: 31 de Agosto de 2018

Fecha de aprobación: 3 de octubre de 2018

Artículo de reflexión

Resumen: La modificación de la Constitución chilena, que establece la elección de los gobernadores regionales, por sufragio popular y directo, no implica per se la alteración de la posición de los gobiernos regionales en la estructura de la administración del Estado. A diferencia de lo sostenido en la doctrina administrativa, en este artículo se llega a caracterizarlos como servicios públicos territorialmente desconcentrados. Se concluye que el ejercicio efectivo de la potestad reglamentaria y el proceso de transferencia de competencias desde el nivel central al regional transformarán a los gobiernos regionales en organismos descentralizados administrativamente que no dependerán jerárquicamente del presidente de la República.

Palabras clave: descentralización administrativa; desconcentración territorial; elección de gobernadores.

Cómo citar: Castillo, E. (2019). Elección de gobernadores regionales y descentralización territorial en Chile. Revista Prolegómenos, 22(43), 109-124.

* Artículo de reflexión con base en la investigación realizada para optar al grado de magíster en Derecho por la Università Degli Studi di Genova y la Universidad Católica de Temuco, año 2011, y a la monografía "Descentralización y proceso constituyente en Chile" de este autor, 2016, presentada en Seminario Proceso Constituyente en Chile: Reflexiones desde las Regiones, organizado por la Asociación de Universidades Regionales - AUR, Programa de Naciones Unidas para el Desarrollo - PNUD, Academia Parlamentaria Cámara de Diputados y el Centro de Extensión del Senado.

** Académico de la Facultad de Ciencias Jurídicas en la Universidad Católica de Temuco (Temuco, Chile). Abogado licenciado en la Universidad de Chile (Santiago, Chile). Magíster en Derecho Universidad Católica de Temuco - Università degli Studi di Genova (Génova, Italia). Correo electrónico: egcastill@uct.cl Código Orcid: 0000-0002-4864-1611. 


\section{Election of Regional Governors and Territorial Decentralization in Chile}

Abstract: The amendment of the Chilean Constitution, which establishes the election of regional governors by popular and direct votes, does not per se imply any modification to the position of regional governments within the administrative structure of the State. As opposed to the administrative doctrine, in this paper, these regional governments are characterized as territorially decentralized public services. Within this context, the author concludes that the effective exercise of regulatory power and the transfer of powers process from the central to the regional level shall eventually transform regional governments into administratively decentralized bodies that will not report hierarchically to the President of the country.

Keywords: Administrative Decentralization; Territorial Deconcentrating; Governor Elections..

\section{Eleição de governadores regionais e descentralização territorial no Chile}

Resumo: A emenda da Constituição chilena, que estabelece a eleição de governadores regionais por meio de votos populares e diretos, não implica, per se, qualquer modificação na posição dos governos regionais dentro da estrutura administrativa do Estado. Ao contrário da doutrina administrativa, neste artigo esses governos regionais são caracterizados como serviços públicos territorialmente descentralizados. Nesse contexto, o autor conclui que o exercício efetivo do poder regulador e do processo de transferência de poderes do nível central para o regional acabará transformando os governos regionais em órgãos administrativamente descentralizados, que não responderão hierarquicamente ao Presidente do país.

Palavras-chave: descentralização administrativa; desconcentração territorial; eleições de governador. 


\section{Introducción}

En Chile el régimen de administración interior del Estado, en el nivel regional, ha sido modificado por la reciente reforma constitucional introducida por la Ley n. ${ }^{\circ} 20.990$, del año 2017, que crea una nueva autoridad regional denominada "gobernador regional”, quien será elegido por sufragio universal en votación directa (artículo 111 de la Constitución de 1980).

La vigencia del artículo 111 de la Constitución, en sus incisos $4^{\circ}$ y $5^{\circ}$, que establecen la elección del gobernador regional, quedó supeditada a la promulgación del proyecto de ley que regula el procedimiento de transferencia de competencias ${ }^{1}$ desde los ministerios y servicios públicos a los gobiernos regionales contemplada en el artículo 114 de la misma Carta. Esta condición quedó plasmada en la Disposición Vigésimo Octava Transitoria de la Constitución Política. Se encuentra en trámite otra modificación a la Ley n. ${ }^{\circ}$ 19.175, Orgánica Constitucional de Gobierno y Administración Regional (en adelante, LOCGAR) para adecuarla a la nueva nomenclatura que elimina la existencia del intendente regional entregando las funciones de gobierno a un delegado presidencial regional (art. 115 bis de la Constitución) y las funciones de administración de la región al Gobierno Regional, encabezado por un gobernador regional electo.

La caracterización del Estado chileno, y consecuentemente de su gobierno y administración, como un caso extremo de centralización puede o no sufrir modificaciones sustanciales con la vigencia de esta reforma. ¿Se convertirán los gobiernos regionales en servicios públicos descentralizados? La pregunta parte de la base de que hoy día no lo son, cuestión que se analizará, y la respuesta permitirá definir la relación de este servicio con el presidente de la República, es decir, una relación jerárquica, en el caso de seguir siendo un servicio desconcentrado, o bien una relación de tutela o supervigilancia, y por tanto un mayor grado de autonomía administrativa, en el caso de ser efectivamente descentralizados.

1 "Proyecto de Ley de Fortalecimiento de los Gobiernos Regionales”. (Boletín 7.963-06).
Por ello los objetivos de este artículo son dilucidar la naturaleza jurídica de los gobiernos regionales en Chile y, a partir de ello, desarrollar sus elementos definitorios como servicios territorialmente desconcentrados y determinar los atributos o poderes que pueden transformar a los gobiernos regionales en servicios descentralizados.

La doctrina administrativista chilena ha sostenido que los gobiernos regionales son organismos descentralizados territorialmente o bien autónomos, cuestiones de las que me ocuparé más adelante. ¿Es esa la naturaleza jurídica de los gobiernos regionales? Responder esta pregunta no es baladí. Como toda la administración del Estado está radicada en el presidente de la República (art. 24 de la Constitución de 1980) hay, en este aspecto, una carencia de un sistema de distribución de competencias, más aún cuando la Carta Fundamental señala que Chile es un Estado unitario. Analizando la transferencia de competencias, actualmente inexistente, desde los ministerios y servicios nacionales a los gobiernos regionales, y la potestad reglamentaria de estos últimos se llega a identificarlos como servicios desconcentrados territorialmente.

Luego se expondrán las condiciones que son necesarias para que se instale en la administración chilena una descentralización regional de carácter territorial basada en el principio de subsidiariedad vertical expresado en el reparto de competencias administrativas, al menos entre los niveles nacional y regional, y en el fortalecimiento de la potestad reglamentaria que tienen los gobiernos regionales.

El problema planteado se analiza desde la perspectiva del Derecho Administrativo y, en consecuencia, no aborda otras facetas del fenómeno como la perspectiva de la elaboración y gestión de políticas públicas o la dimensión política, que indudablemente está presente en todo lo que atañe a la organización y poderes del Estado, cuestiones que corresponden a la ciencia de la administración y a la ciencia política.

Para los efectos de este artículo, se trabajará sobre el texto de la Constitución vigente al momento de redactar estas líneas, es decir, el texto anterior a la modificación constitucional introducida por la Ley n. 20.990 pues, al momento de escribir este artículo, esta última todavía no entra en vigencia 
en virtud de la citada Disposición Vigésimo Octava Transitoria de la Constitución.

\section{La situación actual}

El año 1991 se reformó la Constitución de 1980 creándose un nuevo ente de administración interior consistente en los gobiernos regionales, servicios públicos territoriales, atribución que con anterioridad a la reforma estaba radicada en el intendente regional. Para ello se modificó el entonces Capítulo XIII de la Constitución (hoy Capítulo XIV) incorporando en la normativa sobre gobierno y administración interior del Estado a los gobiernos regionales (Ministerio del Interior, Ley n. ${ }^{\circ}$ 19.097).

En el nuevo texto se establece que "para el ejercicio de sus funciones, el gobierno regional gozará de personalidad jurídica de derecho público y tendrá patrimonio propio" (art. 100, inc. $3^{\circ}$ ). En cambio, en el artículo 107 , inc. $2^{\circ}$, señala que las municipalidades "son corporaciones autónomas de derecho público, con personalidad jurídica y patrimonio propio". Es útil recurrir al debate parlamentario para ilustrar los conceptos en juego.

El Congreso otorgó significado al concepto de "descentralización administrativa", el cual debe entenderse como una transferencia de competencias desde el nivel central a entes jurídicamente diferenciados, es decir, con personalidad jurídica y patrimonio propio, y que no le están jerárquicamente subordinados (Comisiones Unidas del Senado, p. 41).

La inclusión de la "desconcentración" se debe a que no todo se descentraliza, pues se pueden asignar atribuciones a un órgano inferior que tiene competencia para resolver determinadas materias, manteniéndose la supeditación jerárquica al superior (Comisiones Unidas Cámara de Diputados, p. 365).

Varas y Mohor (1992), en referencia a la discusión parlamentaria, señalan que los procesos de descentralización y desconcentración se harán "en conformidad a la ley", de tal manera que la Constitución deja al legislador establecer cuáles funciones y atribuciones serán objeto de descentralización o desconcentración. La Cámara de Diputados reafirmó la idea que la descentralización administrativa se entiende como transferencia de competencias desde el nivel central a entes jurídicamente diferenciados y no subordinados a aquel.

Nada de lo que previó el constituyente derivado se ha cumplido. En efecto, no ha habido transferencia de competencias y la autoridad ejecutiva del ente administrador de la región, el intendente y ejecutivo del Gobierno regional, es una autoridad de exclusiva confianza del presidente de la República y por tanto subordinado a la máxima autoridad del Estado. En Colombia, Jiménez (2011), basándose en la Constitución de 1991 — país que se declara como una república unitaria, descentralizada (artículo $1^{\circ}$ ) 一, distingue entre la descentralización territorial y la descentralización "concebida como mera técnica de gestión ligada al principio decimonónico de 'centralización política y descentralización administrativa', propia del Estado unitario-centralista" (p. 260).

Como ya se adelantara en la introducción de este artículo, la pregunta que surge es si los gobiernos regionales son servicios públicos autónomos, descentralizados o bien desconcentrados, y por lo tanto expresión de una "una técnica de gestión", como señala Jiménez en la idea recién citada. En los párrafos siguientes argumentaré por qué no son servicios autónomos ni descentralizados, como lo sostiene la mayoría de la doctrina, sino que se trata de servicios desconcentrados.

\section{Los gobiernos regionales no son órganos autónomos}

Es evidente que las observaciones que siguen están referidas a la autonomía administrativa y no a la autonomía política, que, según Cordero Quinzacara (2012), "es la que se predica de aquellos Estados compuestos.... Estado federal y los Estados federales, Estado central y regiones. Son casos que también se comprenden bajo la denominación de descentralización política" (p. 16).

Pantoja (2004) sostiene que los gobiernos regionales son autonomías constitucionales porque fueron creados por la propia Constitución que, además, fijó sus funciones y atribuciones, que cuenta con un consejo conformado por miembros 
elegidos por los concejales de la respectiva región ${ }^{2}$ y que "el Presidente de la República carece de las potestades jerárquica y de supervigilancia que ejerce sobre los servicios descentralizados" (p. 301).

Profundizando en este aspecto, Pantoja señala que las autonomías constitucionales nacen de la Constitución, se rigen por disposiciones que aquella establece y por sus propias leyes especiales y "están al margen de los vínculos jurídico-administrativos establecidos por la doctrina clásica: escapan a la línea jerárquica y no admiten sobre ellos el ejercicio de facultades de supervigilancia o tutela" (p. 312). Igual consideración hace respecto de las municipalidades, con la salvedad de que las autoridades superiores municipales -alcalde y concejo municipal - son elegidas en forma directa por los ciudadanos de la comuna, "de modo que el Jefe de Estado no tiene sobre las municipalidades los poderes jurídicos que le asisten sobre los servicios públicos nacionales" (pp. 301-302).

El mismo autor (Pantoja 2008) señala que las funciones administrativas de orden regional y comunal son tales per se y los servicios que las ejecutan - gobiernos regionales y municipios- "son autónomos en su acción, encontrándose al margen de la esfera potestativa que representaba el Jefe de Estado como centro de la función administrativa en todo el país" (p. 195).

La Contraloría General de la República señala que la ley orgánica de gobiernos regionales "no hace más que concretar el principio de descentralización administrativa contenido en el artículo $3^{\circ}$ de la Constitución Política”, agregando que la Constitución:

ha confiado a los gobiernos regionales la administración superior de la región respectiva, confiriéndoles el carácter de órganos autónomos, con personalidad jurídica y patrimonio propios, es inconcluso que por mandato del constituyente tales entes cuentan con la autoridad e independencia suficiente para cumplir, cabal y eficientemente, con dicho cometido (Dictamen n. ${ }^{\circ} 3.714$ del año 2002).

$2 \mathrm{Al}$ momento de publicarse el libro de Pantoja esa era la forma de elección de los consejeros regionales.
No comparto con los autores, ni con el transcrito pronunciamiento de la Contraloría, que señalan que los gobiernos regionales son entes autónomos, por las siguientes razones:

Por de pronto, ni la Constitución ni la Ley Orgánica Constitucional de Gobierno y Administración Regional n. ${ }^{\circ} 19.175$ les otorgan tal carácter.

El hecho de que un organismo público sea creado por la Constitución no trae como consecuencia necesaria que se trate de un órgano autónomo, sin vínculo alguno con el presidente de la República, que es quien tiene a su cargo el gobierno y la administración del Estado, según el artículo 24 de la Constitución. Desde luego, hay organismos creados por la Constitución dotados de autonomía que no son entes descentralizados, como la Contraloría General de la República y el Ministerio Público (Cordero Quinzacara, 2012). También hay órganos o servicios que forman parte de la administración - de acuerdo con el artículo $1^{\circ}$, inciso $2^{\circ}$, de la Ley $n .^{\circ} 18.575$, Orgánica Constitucional de Bases Generales de la Administración del Estado (en adelante, LOCBGAE) - que, teniendo un tratamiento especial en la Constitución, son centralizados, como ocurre con las Fuerzas Armadas y con las Fuerzas de Orden y Seguridad Pública.

Caracterizar a un órgano público como autónomo, sobre los cuales el presidente de la República carece de las potestades de jerarquía y de supervigilancia, significa que su "relación con el poder central o las máximas autoridades gubernativas es tenue o casi inexistente" (Cordero Quinzacara, 2012, p. 16), lo que equivale a un poder de decisión independiente de toda otra autoridad. Por lo demás, es la LOCbGAe la que coloca a los gobiernos regionales como integrantes de la Administración del Estado (arts. $1^{\circ}$ y $21^{\circ}$ ) y, concordante con ello, el artículo 105 de la Ley Orgánica Constitucional de Gobierno y Administración Regional, n. ${ }^{\circ}$ 19.175, dispone que "los gobiernos regionales y los intendentes se relacionarán con el Presidente de la República a través del Ministerio del Interior", fórmula usada para denotar la supervigilancia que la máxima autoridad del país tiene sobre estos organismos. 
No sucede lo mismo con las municipalidades, que constitucionalmente son organismos autónomos. Pero aun así, según los dictámenes n. ${ }^{\text {os }}$ 20.943 y 21.248, ambos de 1993 de la Contraloría General de la República, las municipalidades, como corporaciones autónomas de derecho público, son servicios descentralizados que integran la administración del Estado. En los dictámenes $18642 \mathrm{~N} 92,34.631 \mathrm{~N} 93$ y $14.066 \mathrm{~N} 98$, se señala que "la autonomía municipal constituye un principio de descentralización administrativa", lo que fue ratificado por las leyes n. ${ }^{\circ} 19.097$ (reforma constitucional del año 1991), n. 19.526 (reforma constitucional del artículo 121 de la Constitución, año 1997) y, más recientemente, por la Ley n. ${ }^{\circ} 20.922$, que permite a las municipalidades crear sus propias plantas de funcionarios.

Que la autonomía, en este caso la municipal, constituya "un principio de descentralización administrativa" plantea a la descentralización administrativa un estándar no apreciado suficientemente sobre todo tratándose de servicios descentralizados territorialmente. En este sentido, la autonomía es un elemento constitutivo de la descentralización territorial.

Tampoco la Constitución confiere a los gobiernos regionales el carácter de órganos autónomos y solo señala que "para el ejercicio de sus funciones" contarán con personalidad jurídica de derecho público y patrimonio propio, pero ello no es suficiente para señalarlos como autónomos. Cuando el constituyente o el legislador quieren dotar de autonomía constitucional o legal a un organismo hacen declaración expresa de ello, ya sea en la propia Constitución o en la ley que crea el respectivo servicio público, porque la Constitución establece las formas que debe adquirir la administración y ellas son la descentralización y la desconcentración, ya sea funcional o territorial (artículo $3^{\circ}$, inc. $2^{\circ}$ ), lo que es ratificado posteriormente por la LOCBGAE en su artículo 29, que solo contempla que los servicios públicos son centralizados o descentralizados.

En los artículos 112 y 113 de la Carta Fundamental se señalan las finalidades del Gobierno regional como responsable de la administración superior de la región y ellas son el desarrollo social, cultural y económico de aquella. No se indican las funciones ni las atribuciones de los gobiernos regionales, pues lo que señala el texto constitucional son las atribuciones del intendente, en cuanto ejecutivo de aquel (coordinación, supervigilancia y fiscalización de los servicios públicos que operen en la región) y las atribuciones del consejo regional (que son normativas, resolutivas y fiscalizadoras). Tanto en el caso del intendente como del consejo regional, la Constitución deja al legislador determinar las atribuciones de ambos órganos -intendente y consejo regional- y la forma en que las ejercerán, con la salvedad de que para el caso del consejo regional esas disposiciones deben ser orgánicas constitucionales.

Finalmente, ha sido el propio legislador el que ha dado a los gobiernos regionales un tratamiento distinto al que se da a los órganos autónomos. Así, la Ley n. ${ }^{\circ} 20.285$ sobre Acceso a la Información Pública, en su artículo $2^{\circ}$, excluye de la aplicación de sus disposiciones a la Contraloría y al Banco Central, salvo mención expresa, porque son órganos autónomos, aunque parte de la Administración del Estado, pero incluye a los gobiernos regionales.

\section{Los gobiernos regionales no son órganos descentralizados territorialmente}

La Constitución, por lo tanto, no reconoce a los gobiernos regionales el atributo de autónomos y parte importante de la doctrina los ha caracterizado como órganos descentralizados territorialmente. Así, Ferrada (1999) señala a los gobiernos regionales como órganos descentralizados territorialmente y con vínculo de tutela o supervigilancia del presidente de la República. En el mismo sentido se manifiestan Verdugo, Pfeffer y Nogueira (1994), Verdugo y García (2010), y Silva Cimma (1995). Más recientemente, sostiene la misma opinión Sandra Ponce de León (2015).

Las características de los órganos descentralizados territorialmente que señala Enrique Silva Cimma (1969) resumidamente son los siguientes: órganos creados por el legislador o la propia 
Constitución, dotados de personalidad jurídica de derecho público y patrimonio propio, sin subordinación al poder central, pero sometidos a la supervigilancia de aquel, sus autoridades nombran directamente su personal, tienen autonomía absoluta en el manejo e inversión de su patrimonio, están sujetos a fiscalización y "sus autoridades son propias y se generan directamente por elección popular; delegatarias de la ciudadanía” (p. 130).

Conceptos similares expresa Bermúdez (2014), al señalar que los elementos distintivos de la descentralización territorial son

la competencia en asuntos propios especificados en la ley (...) personalidad jurídica de derecho público y patrimonio propio (...) control de tutela o supervigilancia, (...) la autoridad debe ser representativa de la localidad, (...) debe ser un representante local y no un representante de la Administración (pp. 372-373).

Detengámonos en algunos elementos de los órganos descentralizados territorialmente: personalidad jurídica y patrimonio propio, la forma de generación de las autoridades del órgano descentralizado y la relación de tutela o supervigilancia que tienen respecto del presidente de la República.

\section{Personalidad Jurídica y patrimonio propio}

Con la reforma introducida a la Constitución de 1925 por el Decreto Ley n. ${ }^{\circ} 573$ y por el Decreto Ley n. ${ }^{\circ}$ 575, ambos del año 1974, lo que se hizo fue ordenar un mecanismo de centralización bajo la forma de desconcentración de los servicios públicos. En efecto, las ideas de planificación, regionalización e integración eran componentes del fortalecimiento del poder central y no de desprendimiento de potestades hacia los niveles inferiores, como las regiones y comunas principalmente.

Estas reformas permitieron la creación de un nuevo estatuto de gobierno y administración interior del Estado modificando la división política y administrativa del país en regiones, provincias y comunas. Además, dieron forma al gobierno y la administración en la región, ambos radicados en el intendente regional.

El tema que nos interesa resaltar es que no se puede sostener que las municipalidades — según su conformación, atribuciones, organización interna y origen de sus autoridades - eran en aquella época entes descentralizados. Por el contrario, eran instituciones fuertemente centralizadas, lo que se expresó en el nombramiento y remoción del alcalde por el presidente de la República, a propuesta del intendente regional, siendo un cargo de confianza de la máxima autoridad nacional; en la subordinación del alcalde al gobernador provincial, salvo en las atribuciones privativas de la municipalidad ${ }^{3}$.

De allí que la personalidad jurídica y patrimonio propio es un elemento esencial de una institución descentralizada, en este caso territorialmente, pero no es un elemento definitorio de su naturaleza jurídica pues, como ya vimos, pueden existir entes con personalidad jurídica propia y no ser descentralizados. La personalidad jurídica es, por tanto, un atributo incuestionable de los gobiernos regionales, pero ello no basta para señalarlos como organismos descentralizados.

Pareciera ser que el hecho de que un órgano cuente con personalidad jurídica y patrimonio propio lo hace automáticamente un órgano descentralizado. Sin embargo, ¿qué razonamiento puede llevar a esa conclusión? Lo único es determinar $a$ priori que esa característica - tener personalidad jurídica y patrimonio propio- es la esencial y única que distingue a un órgano descentralizado territorialmente.

Esencial, porque sin personalidad jurídica y patrimonio, separados del ente central, no hay órgano descentralizado, toda vez que no podrá actuar en la vida jurídica - judicial y extrajudicialmente, sino amparado en la personalidad jurídica y el patrimonio fiscal-, aunque tenga atribuciones y cierta autonomía para determinar sus planes y

\footnotetext{
3 El año 1976 se dictó el Decreto Ley n. ${ }^{\circ}$ 1.289, Ley Orgánica de Municipalidades, señalando que éstas "son instituciones de Derecho Público, funcional y territorialmente descentralizadas".
} 
programas, para nombrar su personal o para ejecutar su presupuesto. Ello indudablemente es así.

Es única porque el órgano descentralizado no tendría otras características que no fuera el contar con personalidad y patrimonio propios, separados del ente central. Ello claramente no es así porque además debe caracterizarse por tener cierta autonomía para determinar sus políticas, planes y programas, no estar subordinado jerárquicamente a otro ente del poder central y administrar sus recursos tanto humanos como financieros, incluyendo la recaudación de recursos propios, atribución que en Chile está conferida solo a las municipalidades.

Por ello la existencia de un organismo con personalidad jurídica y patrimonio propio no es sinónimo de organismo o servicio descentralizado territorialmente. Soto Kloss (1992) indica que la desconcentración no solamente es una radicación por ley de atribuciones en un órgano inferior en los servicios centralizados, sino que también puede aplicarse en los servicios regionales como los servicios de vivienda y urbanismo y en los servicios de salud regionales, los cuales cuentan con personalidad jurídica (p. 120).

Ambos servicios cuentan con patrimonio y personalidad jurídica propia y tienen competencia en un territorio determinado - la región o parte de ella en el caso de los Servicios de Salud-, por lo que podría decirse que son organismos descentralizados territorialmente. Sin embargo, y concordando con Soto Kloss, aquellos son organismos desconcentrados expresando la voluntad del legislador de propender a la regionalización y a la eficiencia de la gestión administrativa.

Lo mismo ocurre con los gobiernos regionales los que, teniendo personalidad jurídica y patrimonio propio, persiguen desconcentrar la administración del FNDR, regionalizando la decisión de su inversión y el proceso de aprobación de algunos instrumentos de planificación territorial.

En lo medular, interesa dejar establecido que las propiedades personalidad jurídica y patrimonio no son atributos exclusivos del ente central y de los órganos descentralizados, sino que también pueden serlo, aunque excepcionalmente, de los órganos desconcentrados. Este último caso es el de los gobiernos regionales.

\section{Autoridades propias generadas por la ciudadanía}

La generación de sus propias autoridades es una característica señalada como un elemento esencial de los órganos descentralizados territorialmente (Silva, 1995, pp. 213-214). Según este criterio, en Chile el único órgano descentralizado territorialmente es la municipalidad, pues cumple con todos los requerimientos de este tipo de entes, especialmente con la generación por voluntad popular de sus autoridades ${ }^{4}$.

La reforma constitucional que sustituyó el artículo 113 de la Constitución, contemplando la elección de los consejeros regionales mediante sufragio universal, no cambió el carácter de los gobiernos regionales, toda vez que la máxima autoridad y el órgano ejecutivo del gobierno regional siguió siendo el intendente, quien mantiene la iniciativa en todas las materias que son competencia del órgano.

Si la existencia de autoridades propias generadas por elección popular es un elemento esencial de un órgano descentralizado territorialmente, la caracterización que de los gobiernos regionales hacen los diversos autores citados es errónea, pues aquellos no cuentan todavía con autoridades elegidas por la ciudadanía. Por el contrario, si tal elemento no es esencial, perfectamente podríamos estar en presencia de un organismo descentralizado territorialmente.

Como las autoridades del gobierno regional no son elegidas por sufragio popular, cabe preguntarse quién o quiénes las designan. En el caso de los consejeros regionales, son elegidos por sufragio universal y en votación directa. Pero el órgano ejecutivo, que es el intendente regional, es designado por el presidente de la República, de quien es su

$4 \mathrm{El}$ artículo 119 de la Constitución señala que los concejales serán elegidos por sufragio universal, pueden ser reelegidos y que la ley determinará la forma de elegir al alcalde. Según la Ley n. ${ }^{\circ} 18.695$, artículo 57, los alcaldes son elegidos por sufragio universal. 
representante natural e inmediato en la región, por lo que además es de su exclusiva confianza.

Es decir, en el lenguaje de Silva Cimma (1969), su máxima autoridad no es "propia" ni "se genera directamente por elección popular; delegatarias de la ciudadanía” (pp. 129-130). Esto hace que los gobiernos regionales sean desconocidos por la ciudadanía que los identifica con la intendencia y por tanto como un servicio que depende jerárquicamente y representa al presidente de la República en la región.

\section{La relación de supervigilancia con el presidente de la República}

La forma de generación de la autoridad que encabeza la administración de la región pone, además, en entredicho la supuesta supervigilancia que el presidente tendría sobre el gobierno regional. La supervigilancia se manifiesta principalmente en "la designación de las autoridades superiores de tales órganos" (Bermúdez, 2014, p. 380), citando como ejemplo de órgano descentralizado territorialmente a los gobiernos regionales, pues su autoridad, el intendente, es designado por el presidente de la República. Es decir, en este aspecto los gobiernos regionales, y su autoridad máxima, el intendente y ejecutivo, tendrían el mismo estatus y relación con el presidente que un servicio público descentralizado funcionalmente, quedando sujeto a la supervigilancia de aquel.

Es difícil concebir que el intendente regional pueda depender directamente y seguir las instrucciones presidenciales para el gobierno de la región y a la vez ser la autoridad máxima del ente administrador regional descentralizado teniendo solo la supervigilancia de su superior jerárquico, el presidente de la República. No hay que olvidar que el intendente regional es el jefe superior del servicio público denominado gobierno regional - que administra la región - y es a la vez quien ejerce las funciones del presidente de la República en la región, de acuerdo con las leyes y las "órdenes e instrucciones del Presidente" (artículo 111 de la Constitución).

Si ya se hace cada vez más difícil distinguir los actos de gobierno de los actos de administración cabe preguntarse cómo una autoridad que, según el artículo 11 de la Constitución, tiene relaciones de subordinación jerárquica, como representante natural e inmediato del presidente en la región en el primer caso, y de tutela en el otro, y en ambos casos del presidente de la República, puede abstraerse de las instrucciones u orientaciones del gobierno central al ejercer su función de administración de la región. En otras palabras, la administración supuestamente descentralizada está en función de la actividad gubernativa encomendada constitucionalmente al presidente de la República, con la colaboración de sus ministros (artículo 33 de la Constitución) y de su representante natural e inmediato en la región, que es el intendente regional.

Esta relación jerárquica, según Sayagués Laso (1963), otorga al jerarca todos los poderes propios de la función administrativa y además la dirección y control de los órganos y funcionarios que dependen de él.

\section{Los gobiernos regionales son órganos desconcentrados territorialmente}

La desconcentración es caracterizada como una variante dentro del órgano centralizado (Silva Cimma, 1969, p. 127) mediante la cual se separan ciertas competencias o decisiones para que sean ejercidas por subordinados jerárquicos; es decir, se da al interior del mismo órgano sin crear una persona jurídica nueva o separada del órgano que se desconcentra. Las potestades o poderes jurídicos son "atribuidas en forma exclusiva y excluyente a dicho órgano, que viene a poseerlas como propias" (Soto, 1992, p. 118). Esas potestades son sustraídas del superior jerárquico. En Chile, la desconcentración también se puede dar dentro de un órgano descentralizado que goza de personalidad independiente del poder central (Soto, 1992). Sandra Ponce de León (2015) señala que "no es un sistema de organización administrativa, sino que constituye un mecanismo legal de transferencia de funciones administrativas que opera dentro del sistema centralizado, como en el descentralizado" (p. 75). 
Soto Kloss (1992) señala que la desconcentración puede tener dos finalidades, para agilizar la gestión en el ámbito nacional "pero también lo podrá hacer como mecanismo para concretar la regionalización, esto es a propender a una más ágil gestión administrativa territorial" (p. 120), citando los casos ya mencionados de los Serviu regionales y de los servicios de salud ${ }^{5}$.

De la Vallina Velarde (como se citó en Ponce, 1986) señala que todas las funciones administrativas no se pueden realizar "a través de los órganos centrales superiores, sino que se hace necesario un reparto de competencias públicas entre los órganos centrales y otros entes y órganos que desarrollan su actividad en zonas concretas del territorio nacional" (p. 107).

La Constitución chilena, en su artículo $3^{\circ}$, inciso $2^{\circ}$, atribuye solo a la ley la decisión de desconcentrar, territorial o funcionalmente, lo que concreta el artículo 33 de la Ley n. ${ }^{\circ} 18.575$, Orgánica Constitucional de Bases Generales de la Administración del Estado. Pero nada obsta que sea la propia Constitución la que disponga la desconcentración de un servicio público, aunque ello no es usual, como lo hace el artículo 94 bis, agregado por la reforma constitucional contenida en la Ley n. ${ }^{\circ} 20.860$, del año 2015, que otorga rango constitucional al Servicio Electoral como un organismo autónomo, con personalidad jurídica y patrimonio propio. El artículo dispone en su inciso final que "su forma de desconcentración, las plantas, remuneraciones y estatuto del personal serán establecidas por una

5 Los Servicios de Vivienda y Urbanismo creados por el Decreto Ley n. ${ }^{\circ} 1.305$ del año 1976, en cada una de las regiones del país, tienen una clara subordinación jerárquica al Ministerio a pesar de que su artículo 25 señala que contarán con "personalidad jurídica, con patrimonio distinto del Fisco", pero agrega que son "ejecutores de las políticas, planes y programas que ordene directamente el Ministerio o a través de sus Secretarías Ministeriales", que su artículo 29 dispone que en la asignación y transferencia de vivienda se regirán por los reglamentos e instrucciones del Ministerio, y que el artículo 38 dispone que la provisión de las vacantes de la planta nacional de personal, que comprende al Ministerio, a las Seremi y a los Serviu regionales, "será hecha por el Ministerio". ley”, es decir, la Constitución prescribe que sea un organismo que en su organización se desconcentre en la forma que determine la ley.

Dicho lo anterior, señalo a continuación los fundamentos para considerar a los gobiernos regionales como órganos desconcentrados.

En primer lugar, Silva Cimma (1995) señala que en algunos casos excepcionales la ley dota a un servicio público de personalidad jurídica de derecho público cuando la afectación de bienes es de mayor trascendencia y se requiere mayor independencia para administrarlos, y cita como ejemplos la Dirección General de Crédito Prendario, Dicrep, y la Dirección de Aprovisionamiento del Estado, este último organismo ya desaparecido. En dichas entidades, en su concepto, concurren varios de los caracteres de la administración central desconcentrada. En el caso de la Dicrep, la Ley n. ${ }^{\circ} 4.785$ del año 1928 estableció: "Créase en Santiago la Caja de Crédito Popular, con personalidad jurídica, con el objeto de atender al ahorro y a préstamos". Agregó la ley que en la medida que lo permitan los fondos podrá abrir sucursales. Es decir, la citada institución nació para administrar un fondo y por eso se le otorgó personalidad jurídica, sin ser un servicio descentralizado. Hoy tiene patrimonio propio, otras atribuciones y su ley orgánica la caracteriza como una institución autónoma.

También es el caso de los gobiernos regionales, porque sus inicios se remontan al Decreto Ley n. 575, que en su artículo 24 dispuso: "Sin perjuicio de los fondos que se asignen sectorialmente a las regiones, existe en el Presupuesto de la Nación un Fondo Nacional de Desarrollo Regional, al cual se le destinará a lo menos un 5\% del volumen total de los ingresos".

A partir de 1976 el FNDR fue incorporado anualmente en la Ley de Presupuestos del Sector Público en la partida del Ministerio de Planificación Nacional, Mideplan, y era administrado en cada región por la Secretaría Regional Ministerial de Planificación y Coordinación, Serplac, correspondiendo la decisión final de las inversiones al intendente regional (Decreto Ley n. ${ }^{\circ}$ 575, artículo 5 , número 3 ). 
Por su parte, el texto original del artículo 102 de la Constitución de 1980 estableció la existencia de un consejo regional de desarrollo, órgano asesor del intendente regional en su función de administrar la región. Entre otras atribuciones que el texto constitucional entrega a dicho consejo está la de "resolver la distribución del fondo regional de desarrollo".

En su calidad de órganos administradores superiores de la región (art. 111, inciso $2^{\circ}$, de la Constitución), los gobiernos regionales administran el FNDR, pero sin autonomía respecto del órgano central tutelar, el presidente de la República.

En consecuencia, la principal fuente de recursos de los gobiernos regionales no es propia, sino que proviene del FNDR, que es un fondo de inversión centralizado y el rol de aquellos es ejecutar ese fondo de conformidad con la normativa que anualmente establece la Ley de Presupuestos, principalmente a través de las glosas presupuestarias, y en conformidad con las normas que regulan la inversión pública aplicadas por el Ministerio de Desarrollo Social, antes Mideplan, y el Ministerio de Hacienda.

En otras palabras, se ha regionalizado la administración del FNDR otorgando a los gobiernos regionales -intendente y consejo regional- la atribución de decidir a qué proyectos destinan sus fondos. Esto hizo mucho más eficiente y eficaz la utilización de los recursos del FNDR en cada región y descongestionó a la administración centralizada liberándola de la administración de esos recursos. Eso es desconcentrar.

Concuerdo con Sandra Ponce de León (2015) cuando señala que la desconcentración es un mecanismo legal de transferencia de funciones administrativas, pues ello coincide plenamente con la naturaleza de las atribuciones de los gobiernos regionales que son, sustancialmente, administrar el FNDR y aprobar instrumentos de planificación territorial, solo que en este caso el constituyente derivado y el legislador les otorgaron personalidad jurídica y patrimonio propio. Pero ya vimos que estos elementos también pueden ser atributos de un órgano desconcentrado.

En segundo lugar, refuerza la tesis de la desconcentración que hemos tenido hasta hoy una modalidad de encomendamiento de funciones que algunos ministerios han hecho a los gobiernos regionales mediante la suscripción de convenios.

Hay dos ejemplos de utilización de esta fórmula, uno antes de la reforma al art. 114, del año 2009, y otro posterior a ella. El primero de ellos es la transferencia de las competencias de planificación desde el ex-Ministerio de Planificación a los gobiernos regionales representados por la Subsecretaría de Desarrollo Regional y Administrativo. El Convenio respectivo fue aprobado por Resolución Exenta n. ${ }^{\circ} 215$, del 2 de febrero de 2007, de la Subsecretaría de Desarrollo Regional y Administrativo, Subdere. Como se aprecia, el Convenio no está suscrito por ninguna de las personas jurídicas de derecho público denominadas "gobiernos regionales”, los que actuaron representados por el órgano central, la Subdere. Definitivamente, esto es propio de un órgano desconcentrado territorialmente.

El segundo ejemplo es el "Convenio de Cooperación Para la Ejecución de Procesos de Ordenamiento Territorial Por los Gobiernos Regionales", suscrito entre las subsecretarías de Obras Públicas, la Subsecretaría de Vivienda y Urbanismo y la Subsecretaría de Desarrollo Regional y Administrativo, el 30 de julio de 2010 y aprobado por Resolución Exenta n. ${ }^{\circ}$ 3288, del 28 de septiembre de 2010, del Ministerio del Interior.

En ambos casos, no se trató de un convenio entre un gobierno regional y un ministerio, como lo exige el artículo 107 de la Ley n. ${ }^{\circ}$ 19.175, Orgánica Constitucional de Gobierno y Administración Regional, sino que la Subdere "actuó en representación” de todos los gobiernos regionales del país. Tanto es así que en la resolución de la Subdere que aprueba el convenio no se cita disposición alguna de la ley de gobiernos regionales.

No cabe duda de que esto es expresión de dependencia y no de descentralización.

En tercer lugar, otra consideración merecen las atribuciones de dictar normas de carácter reglamentario. Los gobiernos regionales tienen potestad normativa emanada de la propia Constitución que, en el artículo 113, señala que el consejo regional "será un órgano de carácter normativo, resolutivo y fiscalizador, dentro del ámbito propio de 
competencia del gobierno regional". La LOCGAR n. ${ }^{\circ} 19.175$, en su artículo 16 señala las funciones generales de los gobiernos regionales y en su letra d) establece que una de ellas es la de "dictar normas de carácter general para regular las materias de su competencia, con sujeción a las disposiciones legales y a los decretos supremos reglamentarios". Según la misma disposición, estas normas están sujetas a toma de razón por parte de la Contraloría General de la República y deben ser publicadas en el Diario Oficial.

Pero luego, en su artículo 20, la LOCGAR señala las atribuciones de los gobiernos regionales y la primera de ellas está dedicada a esta materia en los siguientes términos: “a) Aprobar y modificar las normas reglamentarias regionales que le encomienden las leyes, no pudiendo establecer en ellas, para el ejercicio de actividades, requisitos adicionales a los previstos por las respectivas leyes y los reglamentos supremos que las complementen". De acuerdo con el artículo 24, letra g), de la citada ley, es atribución del intendente y ejecutivo del Gobierno Regional presentar y someter a aprobación del consejo regional tales reglamentos "que regulen materias propias de la competencia del gobierno regional, en conformidad a las leyes y a los reglamentos supremos correspondientes". Por su parte, el artículo 36, letra b), señala que corresponde al consejo regional "aprobar los reglamentos regionales".

Estas disposiciones cumplen a cabalidad con el concepto de potestad reglamentaria de ejecución que reconoce la doctrina. El Tribunal Constitucional en la sentencia del Rol 325, considerando $5^{\circ}$ (como se cita en Cordero Vega, 2015), acotando el contenido de esta potestad, la definió señalando que es la "destinada a facilitar, a dar debida aplicación a la ley y cuya causa directa es esta y su origen inmediato en la Carta Política" (p. 147). Agrega Cordero Vega que los reglamentos "desarrollan, pormenorizan o complementan una ley, facilitando la aplicación de los mandatos legales, pero que no pueden innovar y vulnerar el contenido normativo entregado por la ley", señalando los casos en que el reglamento "no ejecuta la ley, sea por exceso o insuficiencia" (pp. 147-148).
El tema está radicado en la potestad normativa de los entes a los cuales la ley otorga ese poder, entre ellos los gobiernos regionales. En el caso de las municipalidades, la Ley n. ${ }^{\circ} 18.695$, en su artículo 12 , inc. $2^{\circ}$, contempla la atribución municipal de dictar "normas generales y obligatorias aplicables a la comunidad".

Según Cordero Vega (2015), no es contrario a la Constitución que un servicio tenga atribuciones normativas, pero con ellas no puede sobrepasar las que el ordenamiento constitucional otorga al presidente y al Congreso, empero su tratamiento del tema está construido bajo la perspectiva de las normas contenidas en circulares e instrucciones, emanadas de organismos fiscalizadores (superintendencias) y otros entes que regulan alguna actividad como el Tribunal de Defensa de la Libre Competencia, el Consejo para la Transparencia, el Servicio de Impuestos Internos, el Servicio de Aduanas, todos los cuales emiten circulares e instrucciones que deben sujetarse a las normas legales y reglamentarias.

Por su parte, Cordero Quinzacara (2010) señala que en la Constitución la potestad reglamentaria no está entregada exclusivamente al presidente de la República y que por lo tanto el legislador puede otorgar esta atribución a órganos administrativos inferiores, ya sea centralizados o descentralizados. Precave que si hay conflicto prevalecerá el instrumento reglamentario dictado por el presidente. Silva Cimma (2009) plantea la derivación de esta facultad de la potestad entregada por el art. 24 de la Constitución al presidente de la República, aunque trata de manera diferenciada la potestad reglamentaria municipal.

Se ha discutido si la potestad reglamentaria de los gobiernos regionales está o no sujeta a una habilitación del legislador o bien puede ser ejercida discrecionalmente. Cordero Quinzacara (1999) da cuenta de los argumentos en uno y otro sentido y sostiene que los gobiernos regionales tienen un poder normativo "limitado" y da las razones de ello.

Por su parte, Ferrada (2002) señala que la potestad reglamentaria de los gobiernos regionales no está sujeta a habilitación legal siempre que se regulen materias propias de dichos entes. En mi opinión, según el citado artículo 20, letra a), de 
la LOCGAR, los gobiernos regionales pueden dictar "las normas reglamentarias regionales que le encomienden las leyes" y a iniciativa del intendente regional, según lo dispone el artículo 24, letra g), de la LOCGAR. La potestad de dictar reglamentos como normas generales y obligatorias aplicables a la comunidad regional no está dentro de las competencias del gobierno regional, sino que solamente aquella que se corresponde con sus atribuciones señaladas en el citado artículo 20 de la LOCGAR y siempre que se trate de "materias propias de la competencia del gobierno regional”, según reza el artículo 24, letra g), de la LOCGAr. Un ejemplo de esta habilitación la encontramos en la misma LOCGAR, que otorga a los gobiernos regionales la atribución de aprobar los instrumentos de planificación territorial contemplados en la Ley General de Urbanismo y Construcciones ${ }^{6}$.

Otra habilitación legal, de carácter anual, en el que la ley encomendó a los gobiernos regionales dictar reglamentos fue el contemplado en las Leyes de Presupuesto $n^{\text {.os }} 20.407,20.481$ y 20.557, de los años 2010, 2011 y 2012, respectivamente ${ }^{7}$. Así las cosas, no es de extrañar que tampoco existan reclamos de ilegalidad en contra de los gobiernos regionales. No se ha utilizado este recurso por cuanto los gobiernos regionales no han dictado resoluciones que afecten el "interés general de la región o

6 Los gobiernos regionales tienen la facultad de aprobar o rechazar las ordenanzas contenidas en los Planes Reguladores Metropolitanos e Intercomunales, los Planes Comunales de comunas no reguladas por Planes Intercomunales o Metropolitanos (artículo 36, letra c, LOCGAR).

7 Estas leyes establecieron que algunos recursos del FNDR (2\% para actividades culturales y el Fondo Regional de Iniciativas Locales) debían ser asignados mediante procesos transparentes y competitivos establecidos en un reglamento. El Dictamen n. ${ }^{\circ} 60.632 / 2012$ de la Contraloría señaló que estos reglamentos debían cumplir con el trámite de toma de razón y ser publicados en el D.O., según lo indica el artículo 16, letra d), de la LocGar. Por ello, a partir de la Ley n. 20.641 , de Presupuestos Para el Sector Público año 2013, la exigencia de regular la asignación de esos recursos por reglamento se reemplazó por instructivos, y así se ha mantenido hasta la Ley n. ${ }^{\circ} 20.981$ de Presupuestos 2017. de sus habitantes", como reza el artículo 108, letra a) de la LOCGAR, o las que se han dictado han sido sobre materias que no implican conductas de las personas, como son aquellos reglamentos que establecen los símbolos y emblemas de la región, entre ellos los de La Araucanía y de Magallanes.

Al contar excepcionalmente con habilitaciones legales y la iniciativa exclusiva del intendente regional -representante natural e inmediato del presidente de la República en la región-, deja a los gobiernos regionales sin ejercer la gran cantidad y diversa índole de funciones que le asigna su ley orgánica constitucional en sus artículos 16 a 19 en el ámbito del ordenamiento territorial, del fomento de las actividades productivas y del desarrollo social y cultural. El único medio para lograr el desarrollo de la región es la atribución de distribuir los recursos del FNDR y otros otorgados por la Constitución ${ }^{8}$ o la ley, y la aprobación de los instrumentos de planificación territorial, según ya se ha señalado.

\section{Hacia la descentralización}

En toda relación entre dos entes administrativos, uno central y otro territorial, surge la necesidad de determinar cuáles son los poderes de uno y otro. Loo (2009) señala la utilidad del principio de subsidiariedad para resolver esta cuestión, entendiendo que en este aspecto el principio deja de atender a la relación Estado/ ciudadano y se ocupa, más bien, de la relación "entre las distintas articulaciones del poder público, mirando a la distribución de competencias al interior de su estructura política" (Loo, 2009, p. 406). Aplicada a la estructura administrativa el principio de subsidiariedad vertical, según el cual tiene competencia la estructura administrativa más cercana a la comunidad, significa abordar el tema de la repartición de las competencias (Loo, 2009).

Esto puede aplicarse a la distribución del poder político, como en los Estados federales y en los

8 Véase el artículo 115, inc. $3^{\circ}$ de la Constitución Política, el contempla las inversiones sectoriales de asignación regional, ISAR. 
autonómicos, y a la distribución del poder de administración, como en el Estado unitario. Los autores Martínez y Aguiló (1982) sostienen que hay tres modelos de distribución. En el primero, todo lo no atribuido expresamente a la competencia del poder central (se listan las competencias del nivel central) permanece en los Estados miembros; el segundo usa el mecanismo inverso, es decir, se listan las competencias de las provincias, de manera que todo lo que no esté señalado como competencia exclusiva de los entes provinciales y las no incluidas pertenecen al poder central. En estos dos sistemas se presenta el problema de las competencias residuales que quedan en las provincias y en el poder central, respectivamente. En el tercer sistema, además de las exclusivas del nivel central y de la provincia, aparecen las materias compartidas entre el nivel central y el provincial, donde el primero fija las normas generales y el segundo las complementa y/o aplica. En otras palabras, en el campo administrativo los entes subnacionales (regiones, provincias, estados, departamentos) tienen facultades de ejecutar vía reglamento las leyes que el poder central dicta en las materias compartidas. El elemento común a estos tres sistemas es que ellos están establecidos en la Constitución.

La Constitución de 1980 no estableció un sistema de distribución de competencias entre los órganos nacionales y regionales porque todas las competencias están radicadas en la administración central bajo la fórmula del artículo $3^{\circ}$ (Chile es un Estado unitario) y del artículo 24, que prescribe que "el gobierno y la administración del Estado corresponden al Presidente de la República, quien es el Jefe del Estado”. En consecuencia, todas las competencias están radicadas en él. Ponce de León (2015) señala que el artículo 24 citado reconoce el principio de unidad administrativa, en virtud del cual "toda la Administración del Estado está confiada al Presidente de la República" (p. 73).

Concordante con lo anterior, la Ley n. ${ }^{\circ} 19.175$ LOCGAR, en su artículo 106, señala que "las competencias atribuidas por esta ley a los gobiernos regionales no afectarán las funciones y atribuciones que correspondan a la Administración Pública nacional, en todo lo que expresamente no haya sido encomendado a los gobiernos regionales". Esta disposición, de rango legal, refuerza el sistema de distribución de competencias existente al radicarlas todas en el nivel de la administración central, salvo que la misma ley de gobiernos regionales contemple una excepción expresa, la cual también debe sujetarse a las leyes y reglamentos nacionales.

Sin embargo, estimo que tal inconveniente ha sido, en parte, removido por el artículo 114, al establecer que el presidente de la República transferirá "a uno o más gobiernos regionales" una o más competencias en materias de ordenamiento territorial, fomento productivo y desarrollo social y cultural $^{9}$, y actualmente está en tramitación el proyecto de ley que "determinará la forma y el modo" (art. 114 de la Constitución) en que el presidente transferirá dichas competencias ${ }^{10}$.

El autor Delooz (2015) señala que el sistema iniciado el año 1974 con la creación de las regiones "no es más que una desconcentralización” (p. 107). Para ello señala que tal sistema es una desconcentración como forma de adaptación a la centralización; en suma, fue la desconcentración aplicada al nivel regional (Delooz, 2015). Señala el autor que "la apariencia de descentralización apenas disimula fenómenos de desconcentración, entonces de centralización" (Delooz, 2015, p. 111).

Concuerdo con esa opinión, solo que la introducción de un nuevo vocablo - la desconcentralización- puede prestarse a confusiones aplicado a la realidad chilena, que en el artículo $3^{\circ}$ de la Constitución Política y en la Ley n. ${ }^{\circ} 18.575$, Orgánica Constitucional de Bases Generales de Administración del Estado, reconoce la administración centralizada y descentralizada y, en ambos casos, con órganos desconcentrados.

9 La Ley n. ${ }^{\circ} 20.990$ incluyó una modificación en que se reemplaza la expresión "el Presidente de la República podrá transferir", por "transferirá".

10 En el Proyecto de Ley de Fortalecimiento de los Gobiernos Regionales se propone que sea mediante Decreto Supremo del presidente de la República. 


\section{Conclusiones}

¿Por qué resulta posible concluir que los gobiernos regionales buscarán constituirse como organismos descentralizados administrativamente después de que la Reforma Constitucional introducida por la Ley n. 20.990 entre en vigencia?

La Ley n. 20.990 reformó la Constitución en dos sentidos. En primer lugar, separó el cargo de intendente del cargo de intendente y ejecutivo del gobierno regional reemplazándolos por el delegado presidencial regional y el gobernador regional, respectivamente. En segundo lugar, la autoridad máxima de la administración regional, el gobernador regional, será elegido por sufragio universal y directo por los electores de la región, y presidirá el consejo regional, órgano también electo por sufragio universal.

Se elimina así del texto de la Constitución el vocablo "intendente", autoridad creada en las postrimerías de la Colonia (Bocksang, 2015, p. 90), y que se conservó a través de la historia constitucional de Chile.

Estas modificaciones son sustanciales porque la administración regional no dependerá jerárquicamente del presidente de la República y, si se mantienen las disposiciones actuales de la Ley n. ${ }^{\circ} 19.175$, en especial el artículo 105, el gobernador regional se relacionará con aquel a través del Ministerio del Interior. En tal condición, es preciso resolver si estará o no sometido a su supervigilancia, teniendo presente que el artículo 106 de la citada ley orgánica señala que las competencias de los gobiernos regionales "no afectarán las funciones y atribuciones que correspondan a la Administración Pública nacional, en todo lo que expresamente no haya sido encomendado a los gobiernos regionales". Quien sí dependerá jerárquicamente del presidente será el delegado presidencial regional, porque será su representante natural e inmediato en la región (Constitución Política, artículo 115 bis).

Como la elección de gobernadores tendrá lugar una vez aprobada la Ley de Fortalecimiento de los Gobiernos Regionales, se activarán los mecanismos de transferencia de competencias de los ministerios y servicios públicos a los gobiernos regionales, que aquella contempla, abriendo así otro camino de descentralización administrativa territorial.
Queda por dilucidar cómo evoluciona la transferencia de competencias prevista en el artículo 114 de la Constitución desde los ministerios o servicios públicos a los gobiernos regionales y si se fortalece la potestad de los gobiernos regionales para dictar reglamentos, ambas atribuciones asentadas en que sus autoridades - gobernador regional y consejo regional- serán representantes de la ciudadanía, por lo que contarán con legitimidad para dictar normas de carácter general en su región (Cordero, 1999). Estimo que son dos atribuciones básicas, además de la elección del gobernador regional, para avanzar en la descentralización administrativa regional, superando así la desconcentración administrativa como técnica de gestión administrativa territorial.

\section{Referencias}

Bermúdez, J. (2014). Derecho administrativo general. Santiago de Chile: Editorial Thomson Reuters.

Bocksang, G. (2015). Intendentes en el Primer Período Patrio de Chile. En: G. Bocksang Hola y J. L. Lara Arroyo (Coords.), Administración territorial de Chile. Estudios sobre descentralización y desconcentración administrativas (pp. 89-106). Santiago de Chile: Editorial Thomson Reuters.

Comisiones Unidas del Senado (s.f.). Historia de la Ley $n$. 19.097. Primer Informe. Biblioteca del Congreso Nacional.

Comisiones Unidas Cámara de Diputados (s.f.). Historia de la Ley n. ${ }^{\circ}$ 19.097. Informe. Biblioteca del Congreso Nacional.

Cordero, E. (2010). Las normas administrativas y el sistema de fuentes. Revista de Derecho de la Universidad Católica del Norte, 17(1). Coquimbo, Chile.

Cordero, E. (2012). "La administración del Estado en Chile y el concepto de autonomía”. En: La Contraloría General de la República: 85 años de vida institucional (19272012). Monografías. 1a. ed. Santiago de Chile: Edición Contraloría General de la República.

Cordero E. (1999). La potestad reglamentaria de las entidades territoriales... Revista de Derecho de la Universidad Católica del Norte. Antofagasta, Chile.

Cordero, L. (2015). Lecciones de derecho administrativo. Santiago de Chile: Editorial Thomson Reuters.

Delooz, B. (2015). "El dilema de la regionalización chilena. ¿Más desconcentralización o 'auténtica' autonomía 
regional?”. En: G. Bocksang Hola y J. L. Lara Arroyo (Coords.), Estudios sobre descentralización y desconcentración administrativas (pp. 107-128). Santiago de Chile. Editorial Thomson Reuters.

Ferrada, J. C. (1999). El Estado administrador de Chile: de unitario centralizado a descentralizado y desconcentrado. Revista de Derecho de la Universidad Austral de Chile, 10(1). Valdivia, Chile.

Ferrada, J. C. (2002). La potestad reglamentaria de los gobiernos regionales: algunas notas preliminares. Revista de Derecho de la Universidad Católica de Valparaíso, 23. Valparaíso, Chile.

Jiménez, W. (2012). Tres inconsistencias de la Constitución del 91 frente al tema territorial. Revista Prolegómenos. Derechos y Valores, 15(28). Facultad de Derecho, Universidad Militar Nueva Granada. Bogotá, Colombia.

Loo, M. (2009). La disciplina constitucional del principio de subsidiariedad en Italia y Chile. Revista de Derecho de la Pontificia Universidad Católica de Valparaíso, 33(2). Valparaíso, Chile.

Martínez, M. y Aguiló, Ll. (1982). Lecciones de derecho constitucional español. Tomo 2 Derecho autonómico. Valencia, España: Editorial Fernando-Torres Editor S.A.

Pantoja, R. (2004). La organización administrativa del Estado. Santiago de Chile: Editorial Jurídica de Chile.

Pantoja, R. (2008). "La tipología asumida por la administración pública como función estatal...". En: Derecho administrativo. 120 Años de Cátedra. Santiago de Chile: Editorial Jurídica de Chile.

Pfeffer, E. (1990). Manual de derecho constitucional, Tomo 1. Santiago de Chile: Ediar Conosur Ltda.

Ponce, J. (1986). La desconcentración administrativa. Estudio teórico-doctrinario. Revista de Administración Pública, 67-68, 97-122. Instituto Nacional de Administración Pública. Universidad Autónoma de México.

Ponce de León, S. (2015). “Bases de la organización administrativa en Chile”. En: G. Bocksang Hola y J. L. Lara Arroyo (Coords.), Estudios sobre descentralización y desconcentración administrativas (pp. 39-85). Santiago de Chile. Editorial Thomson Reuters.

Sayagués, E. (1963). Tratado de derecho administrativo. Tercera Edición. Volumen I. Montevideo.

Silva, E. (1969). Derecho administrativo chileno y comparado, Tomo 2. Santiago de Chile: Editorial Jurídica de Chile.

Silva, E. (1995). Derecho administrativo chileno y comparado. El Servicio Público. Santiago de Chile: Editorial Jurídica de Chile.
Silva, E. (2009). Derecho administrativo chileno y comparado. Introducción y fuentes. Santiago de Chile: Editorial Jurídica de Chile.

Soto, E. (1992). La desconcentración en el derecho administrativo chileno. Revista de Derecho Público, 51/52. Facultad de Derecho Universidad de Chile.

Varas, P. y Mohor, S. (1992). Reforma regional, provincial y comunal. Santiago de Chile: Editorial Jurídica de Chile.

Verdugo, M., Pfeffer, E. y Nogueira, H. (1994). Derecho constitucional, Tomo 2. Santiago de Chile: Editorial Jurídica de Chile.

Verdugo, M. y García, A.M. (2010). Manual de derecho político, instituciones políticas, Tomo 1. Reimpresión, ed. Segunda. Santiago de Chile: Editorial Jurídica de Chile. 